\title{
DISORDERED REDOX METABOLISM OF BRAIN CELLS IN RATS EXPOSED TO LOW DOSES OF IONIZING RADIATION OR UHF ELECTROMAGNETIC RADIATION
}

\author{
A.P. Burlaka*, M.O. Druzhyna, A.V. Vovk, S.M. Lukin \\ R.E. Kavetsky Institute of Experimental Pathology, Oncology and Radiobiology, NASof Ukraine, Kyiv 03022, Ukraine
}

Aim: To investigate the changes of redox-state of mammalian brain cells as the critical factor of initiation and formation of radiation damage of biological structures in setting of continuous exposure to low doses of ionizing radiation or fractionated ultra high frequency electromagnetic radiation (UHF EMR) at non-thermal levels. Materials and Methods: The influence of low-intensity ionizing radiation was studied on outbred female rats kept for 1.5 years in the Chernobyl accident zone. The effects of total EMR in the UHF band of non-thermal spectrum were investigated on Wistar rats. The rate of formation of superoxide radicals and the rate of NO synthesis in mitochondria were determined by the EPR. Results: After exposure to ionizing or UHF radiation, the levels of ubisemiquinone in brain tissue of rats decreased by 3 and 1.8 times, respectively. The content of NO-FeS-protein complexes in both groups increased significantly $(p<0.05)$. In the conditions of ionizing or EMR the rates of superoxide radical generation in electron-transport chain of brain cell mitochondria increased by 1.5 - and 2 -fold, respectively (p $<0.05)$. In brain tissue of rats kept in the Chernobyl zone, significant increase of NO content was registered; similar effect was observed in rats treated with UHFR $(\mathrm{p}<\mathbf{0 . 0 5})$. Conclusions: The detected changes in the electron transport chain of mitochondria of brain cells upon low-intensity irradiation or UHF EMR cause the metabolic reprogramming of cell mitochondria that increases the rate of superoxide radical generation and nitric oxide, which may initiate the development of neurodegenerative diseases and cancer. This article is part of a Special Issue entitled "The Chornobyl Nuclear Accident: Thirty Years After".

Key Words: ionizing radiation, electromagnetic radiation, superoxide radicals, nitric oxide, mitochondria.

Environmental contamination with radionuclides in some regions of Ukraine due to Chernobyl catastrophe substantiates the studies of the effect of low dose irradiation on living objects, in particular the features of radiation-induced carcinogenesis [1-3]. Along with the generally recognized risk factors of cancer development there are the anthropogenic negative factors affecting morbidity. Examples of such factors are electric and magnetic fields. The wide use of electromagnetic radiation (EMR) in various spheres of human activity could result in its thousand fold higher level than the natural electromagnetic background.

It has been shown that a wide range of diseases are associated with the dysfunction of mitochondria, in particular their electron transport chain (ETC), which manifests itself primarily in disorder of the energy exchange. According to modern biophysical and biochemical views, biological membranes are the most vulnerable to the action of ionizing radiation. Radicalcreating centers in ETC of membranes of mitochondria and endoplasmic reticulum initiate the development of chain free-radical reactions with following DNA dysfunction [4-10].

The aim of our study was determination of changes of redox-state of mammalian brain cells as the critical factor of starting and formation of radiation damage of biological structures in conditions of continuous exposure to low doses of ionizing radiation and fractionated ultra high frequency (UHF)-irradiation at non-thermal levels.

Submitted: June 24, 2016.

${ }^{\star}$ Correspondence: E-mail: apburlaka@gmail.com Abbreviations used: EFD - energy flux density; EMR - electromagnetic radiation; ETC - electron transport chain; mtNOS - mitochondrial nitric oxide synthase; UHF - ultra high frequency.

\section{MATERIALS AND METHODS}

The study of influence of low-intensity radiation on an organism was carried out on 126 outbred female rats bred in the vivarium of R.E. Kavetsky Institute of Experimental Pathology, Oncology and Radiobiology (IEPOR) of the NAS of Ukraine (Kyiv), which were kept for 1.5 years in the Chernobyl accident zone and were fed with nutriment contaminated with radionuclides (200-250 Bq per day), in particular ${ }^{134} \mathrm{Ce},{ }^{37} \mathrm{Cs},{ }^{90} \mathrm{Sr}$, ${ }^{239} \mathrm{Pu},{ }^{241} \mathrm{Pu},{ }^{241} \mathrm{Am}$, etc. The control group of 25 animals was kept on the usual diet in the vivarium of IEPOR.

The effects of EMR in the UHF band on an organism were studied on 95 Wistar male rats, which were kept on the usual diet of the vivarium; the average weight of the animals was $0.20 \pm 0.02 \mathrm{~kg}$. The animals were housed into 2 groups. Animals of the experimental group ( $n=$ 80) were exposed to total UHF irradiation of non-thermal spectrum using the generator "Volna" (Ukraine) with impulse modulation: pulse duration $-2 \mathrm{~ms}$, pulse separation - $10 \mathrm{Ms}$; carrier frequency $-0.465 \mathrm{GHz}$; duration of an exposure session - $17.5 \mathrm{~min}$. The second group consisted from 15 intact animals (the control group).

The maintenance and manipulations with the animals were carried out in compliance with clauses of the General ethical principles of experiments on animals, approved by the First National Congress of Bioethics (Kyiv, 2001), and guided by terms of the reference of the European Convention for the Protection of Vertebrate Animals used for Experimental and other Scientific Purposes (Strasbourg, 1985).

For irradiation, we have chosen the maximal permissible energetic load on the radar system operators. The experimental animals were exposed to energy flux density (EFD) of 1.0-6.0 mW/cm². A quasi anechoic screened 
camera $80.0 \times 70.0 \mathrm{~cm}$ was used. The irregularity of electromagnetic field in the working area was $19.5 \%$, linear polarization, average EFD in the area of exposure $1.0-6.0 \mathrm{~mW} / \mathrm{cm}^{2}$, output power of the generator $20 \mathrm{~W}$, average EFD $40.0-60.0 \mathrm{~mW} / \mathrm{cm}^{2}$. The animals were triply exposed to radiation with three-day intervals. The number of animals for 1 exposure was 5 rats in the working area.

The rate of superoxide radical generation in brain tissue of rats was determined using spin traps technology. Brain tissue homogenate was mixed with spin trap that is selectively accumulated in mitochondria, namely 1-hydroxy-2,2-6,6-tetramethyl-4-oxo-piperidine hydrochloride (TEMPONE-H). The measurement was done by the EPR in special quartz cuvettes without paramagnetic inclusions at $20{ }^{\circ} \mathrm{C}$ [11]. To determine the content of NO and NO-FeS-proteins of N-type by the EPR at low temperature regimen, the samples of brain tissue were prepared using special press die. Activation of NO synthesis in mitochondria was determined using diethyldithiocarbamate [12]. The levels of NO-FeS-proteins of N-type complexes in mitochondria and $\mathrm{NO}$ were registered by the EPR method at the temperature of liquid nitrogen in paramagnetic free quartz dewar [11]. The EPR spectra were registered at $\mathrm{T}=77 \mathrm{~K}$ in parallel with independent intensity standard - ruby monocrystal of special orientation with a known number of paramagnetic centers.

The significance of differences between the studied indexes in the groups was assessed by Student's $t$-test.

\section{RESULTS AND DISCUSSION}

The action of ionizing and non-ionizing radiation on brain cell mitochondria of experimental animals resulted in the irregularities of functioning of molecular electron transporters, in particular FeS-proteins and ubisemiquinone (Fig. 1).

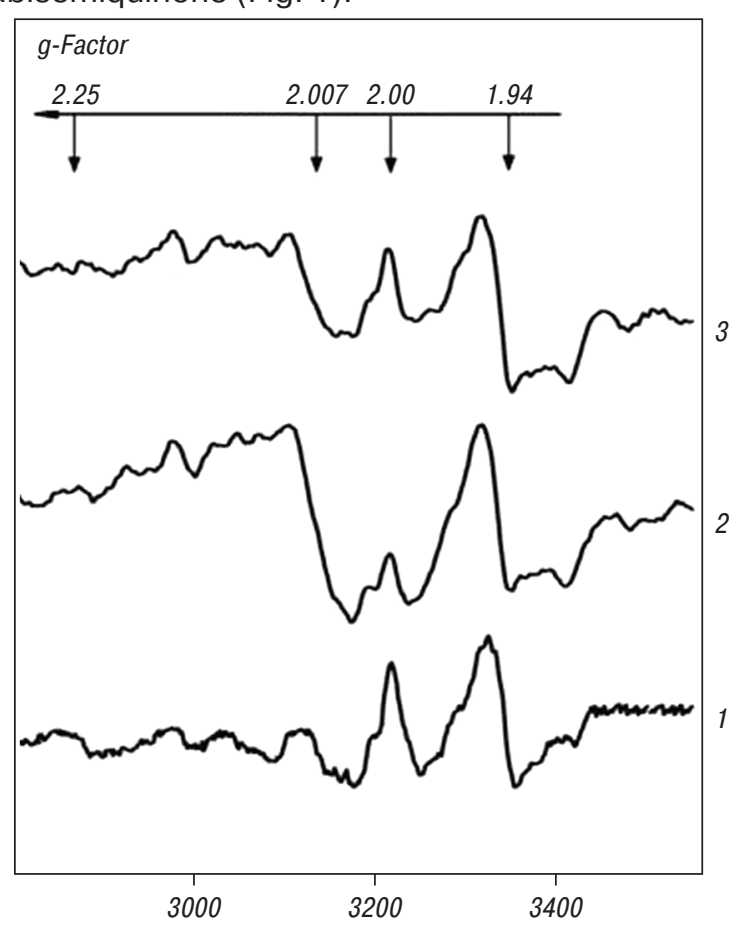

Fig. 1. State of ETC in brain tissue of rats: 1 - intact rats; 2 rats kept in the Chernobyl accident zone; $3-14$ days after the action of EMR in the UHF band
After the animals had been kept in the Chernobyl accident zone, the 3 times reduction in ubisemiquinone levels $(g=2.00)$ and the accumulation of complexes NO-FeS-proteins $(g=2.007)$ were observed compared with the control values. Under these conditions, the FeS-proteins of III protein electron transport complex $(b c 1)$ are activated $(g=1.94)$. This kind of change in the ETC in brain cells was registered in the animals after impulse electromagnetic irradiation. The detected changes in the ETC of mitochondria of brain cells cause the metabolic reprogramming of cell mitochondria that increases the rate of superoxide radical generation and the formation of cellular hypoxia. Metabolic reprogramming of mitochondria, which occur under the influence of low-intensity irradiation and irradiation by UHF EMR, causes changes in the functioning of cells [3-7].

The results of investigation of the rate of superoxide radical generation in mitochondria of brain cells of animals that were exposed to low-intensity ionizing radiation and UHF EMR are shown in Fig. 2.

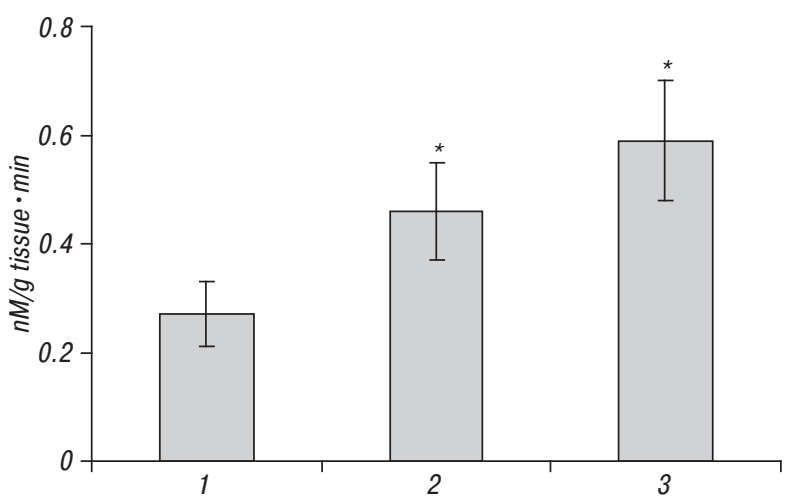

Fig. 2. Rate of superoxide radical generation in mitochondria of brain cells: 1 - intact rats; 2 - rats kept in the Chernobyl accident zone; $3-14$ days after the action of EMR in the UHF band. ${ }^{*} p<0.05$ compared to control

The rate of superoxide radical generation in the ETC of mitochondria of brain cells in the intact animals was $0.27 \pm 0.06 \mathrm{nM} / \mathrm{g}$ tissue $\cdot \mathrm{min}$. In the animals exposed to continuous action of ionizing radiation, the rate of superoxide radical generation in mitochondria of brain cells increased to $0.46 \pm 0.09 \mathrm{nM} / \mathrm{g}$ tissue $\cdot \min$. In mitochondria of cells of the animals exposed to UHFEMR in doses adequate to the maximal permissible energetic load for the radar system operators the rate of superoxide radical generation significantly differs from the control values and was $0.59 \pm 0.11 \mathrm{nM} / \mathrm{g}$ tissue $\cdot \min$. Thus, energy of both the ionizing and UHF-band radiation interacting with the protein electron transport complexes of mitochondria of brain cells (FeS-proteins) causes mitochondria dysfunction and changes in the mechanism of electron transport, consequently, increases the rate of superoxide radical generation, which, in turn, may initiate the development of neurodegenerative diseases and cancer $[2,5,7,10]$.

The results of investigation of NO levels in mitochondria of brain cells in animals that were exposed to the influence of low-intensity ionizing and UHF EMR are shown in Fig. 3. 


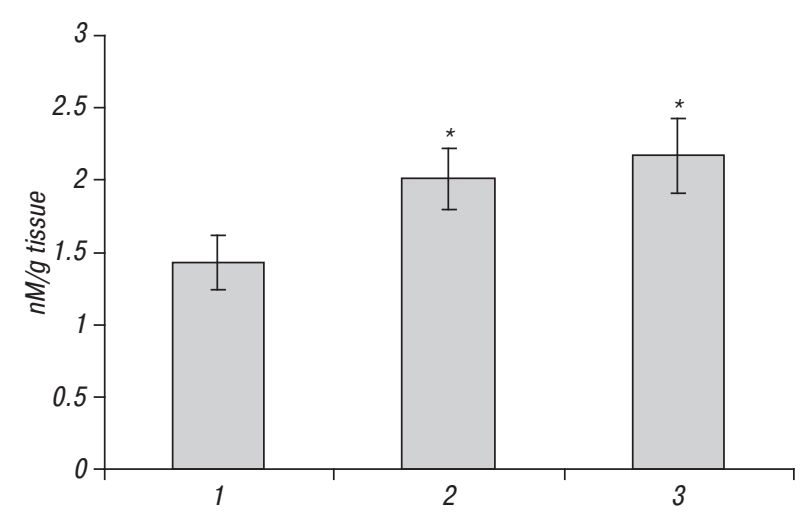

Fig. 3. Levels of NO in mitochondria of brain cells: 1 - intact rats; 2 - rats kept in the Chernobyl accident zone; $3-14$ days after the action of EMR in the UHF band. ${ }^{*} p<0.05$ compared to control

We have registered an increase in levels of NO synthesis in mitochondria of brain cells of the animals in terms of their irradiation in the Chernobyl accident zone (2.01 $\pm 0.21 \mathrm{nM} / \mathrm{g}$ tissue) compared with the intact animals ( $1.43 \pm 0.19 \mathrm{nM} / \mathrm{g}$ tissue). UHF EMR also causes an increase in activity of mitochondrial nitric oxide synthase (mtNOS) $(2.17 \pm 0.26 \mathrm{nM} / \mathrm{g}$ tissue) compared with the non exposed animals.

Fig. 4 shows the data on levels of NO-FeS-proteins in mitochondria of brain cells of the animals exposed to ionizing radiation $(0.67 \pm 0.19$ relative units; $R U)$ and impulse EMR in the UHF band $(0.37 \pm 0.10 \mathrm{RU})$ in comparison with the intact animals $(0.15 \pm 0.06 \mathrm{RU})$.

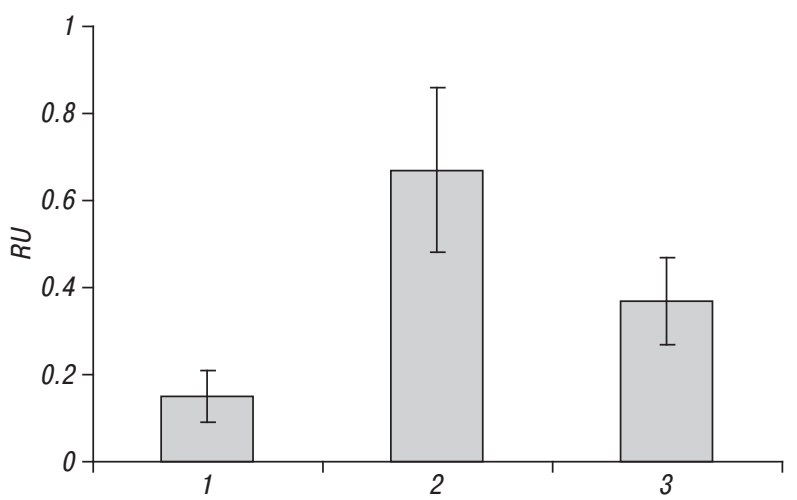

Fig. 4. Levels of NO-FeS-proteins complexes in ETC of mitochondria of brain cells: 1 - intact rats; 2 - rats kept in the Chernobyl accident zone; $3-14$ days after the action of EMR in the UHF band. ${ }^{*} p<0.05$ compared to control

In conclusion, the long-lasting influence of low doses of ionizing radiation and fractionated UHF irradiation lead to significant disorders of functioning of mitochondria. Violation of the mechanism of electron transport in ETC of mitochondria, activation of mtNOS under the influence of UHF EMR initiates the superoxide radical generation in mitochondria. The structure of mtNOS is similar to the inducible NOS, but the mechanism of its activation is functioning constitutively, and it plays a key role in the regulation of mitochondrial transmembrane gradient $(\Delta \mathrm{pH})$ and the rate of electron transport [1315]. Effects of mitochondrial respiration are determined by the output NO generation level, the amount of which depends on the influence of environmental factors such as the levels of UHF EMR, and on the state of neurohumoral mechanisms. An increase in NO levels causes the dysfunction of FeS-proteins of the ETC of mitochondria, increased levels of superoxide radicals, reduced synthesis of adenosine triphosphate, formation of cellular hypoxia and activation of redox-dependent enzymes, in particular metalloproteinase, VEGF $[16,17]$. Mitochondria coordinate the signaling pathways determining the cell death under the conditions of EMR influence, related to the development of inflammatory processes, the initiation of which is registered in various organs of animals, especially in the brain [18]. Mitochondrial dysfunction, associated with the radiation load, leads to the activation of unregulated increase in the rate of superoxide radical generation in cells (mitochondria, cytochrome P450) and increased inflammation and initiation of superoxide-dependent cancer development [16, 18-21].

\section{REFERENCES}

1. Sidorik E, Burlaka A. Molecular mechanisms of cell alteration caused by chronic exposure to low intensity ionizing radiation due to Chernobyl accident. Exp Oncol 2000; 22: 179-85 (in Russian).

2. Sidorik E, Burlaka A, Druzhina N. Generation of nitrosyl complexes of nonheme iron of electron transport chain of mitochondria in liver and kidney under the long term low intensity radiation in zone of the Chernobyl accident. Report NAS Ukraine 1995; 12: 127-9 (in Ukrainian).

3. Tseng BP, Giedzinski E, Izadi A, et al. Functional consequences of radiation-induced oxidative stress in cultured neural stem cells and the brain exposed to charged particle irradiation. Antioxid Redox Signal 2014; 20: 1410-22.

4. Burlaka A, Tsybulin O, Sidorik E, et al. Overproduction of free radical species in embryonal cells exposed to low intensity radiofrequency radiation. Exp Oncol 2013; 35: 219-25.

5. Hao YH, Zhao L, Peng RY. Effects of microwave radiation on brain energy metabolism and related mechanisms. Mil Med Res 2015; 2: 4.

6. Tsybulin O, Sidorik E, Kyrylenko S, et al. GSM $900 \mathrm{MHz}$ microwave radiation affects embryo development of Japanese quails. Electromagn Biol Med 2012; 31: 75-86.

7. Consales C, Merla C, Marino C, Benassi B. Electromagnetic fields, oxidative stress, and neurodegeneration. Int J Cell Biol 2012; 2012: 683897.

8. Burlaka AP, Tsybulin OS, Sidorik EP, et al. Oxidativeinduced damages in embryonal cells of Japanese quail under the exposure to radiofrequency radiation of GSM $900 \mathrm{MHz}$. Report NAS Ukraine 2013; 12: 165-71 (in Ukrainian).

9. Burlaka A, Selyuk M, Gafurov M, et al. Changes in mitochondrial functioning with electromagnetic radiation of ultra high frequency as revealed by electron paramagnetic resonance methods. Int J Radiat Biol 2014; 90: 357-62.

10. Kempf SJ, Azimzadeh O, Atkinson MJ, Tapio S. Long-term effects of ionising radiation on the brain: cause for concern? Radiat Environ Biophys 2013; 52: 5-16.

11. Burlaka AP, Ganusevich II, Golotiuk VV, et al. Superoxide- and NO-dependent mechanisms of antitumor and antimetastatic effect of L-arginine hydrochloride and coenzyme $Q_{10}$. Exp Oncol 2016; 38: 31-5.

12. Burlaka AP, Sidorik EP, Ganusevich II, et al. High formation of superoxide anion and nitric oxide, and matrix metalloproteinases activity in vascular wall of rectal carcinoma vessels. Exp Oncol 2006; 28: 323-5.

13. Haynes V, Elfering S, Traaseth N, Giulivi C. Mitochondrial nitric-oxide synthase: enzyme expression, characterization, and regulation. J Bioenerget Biomembran 2004; 36: 341-6. 
14. Choudhari SK, Chaudhary M, Bagde S, et al. Nitric oxide and cancer: a review. World J Surg Oncol 2013; 11: 118.

15. Lacza Z, Pankotai E, Csordas A, et al. Mitochondrial $\mathrm{NO}$ and reactive nitrogen species production: does mtNOS exist? Nitric Oxide 2006; 14: 162-8.

16. Burlaka AP, Sidorik EP. Redox-dependent signal molecules in mechanisms of tumor process. Kyiv: Naukova dumka 2014. 255 p. (in Ukrainian).

17. Cheng $H$, Wang L, Mollica M, et al. Nitric oxide in cancer metastasis. Cancer Lett 2014; 353: 1-7.
18. Zuo H, Lin T, Wang D, et al. Neural cell apoptosis induced by microwave exposure through mitochondriadependent caspase-3 pathway. Int J Med Sci 2014; 11: 426-35.

19. Tschopp J. Mitochondria: sovereign of inflammation? Eur J Immunol 2011; 41: 1196-202.

20. Naik E, Dixit VM. Mitochondrial reactive oxygen species drive proinflammatory cytokine production. J Exp Med 2011; 208: 417-20.

21. Sullivan LB, Chandel NS. Mitochondrial reactive oxygen species and cancer. Cancer Metab 2014; 2: 17. 